\title{
Angioneurotic oedema and urticaria induced by hyoscine butylbromide
}

\author{
AnNe C. R. Robinson* \\ M.B., M.R.C.P.I., D.C.H.
}

MARY TEELING

M.B., M.R.C.P.I.

\author{
Department of Clinical Medicine, St James's Hospital, Dublin
}

\begin{abstract}
Summary
A case of angioneurotic oedema and urticaria developing during therapy with hyoscine butylbromide is described. It is believed to be the first reported.
\end{abstract}

\section{Introduction}

Hyoscine butylbromide (Buscopan) is an anticholinergic agent with central and peripheral actions. It is almost entirely metabolized in the body (Reichel, 1976).

\section{Case report}

A 23-year-old white female was admitted to hospital following the sudden onset of swelling of her eyelids, urticarial lesions on her trunk and extremities and a feeling of tightness in her throat. The patient was being treated symptomatically for abdominal colic with hyoscine butylbromide (Buscopan) $10 \mathrm{mg}$ three times a day and had taken one week's supply before the onset of her symptoms. There was no past or family history of atopy. On examination, she had oedema of the eyelids and widespread urticarial eruptions on her trunk and limbs. She was afebrile and there was no lymphadenopathy. Laboratory investigations included full blood count and differential, antibody screen, liver function tests, cryoglobulins and $\mathrm{C}_{1}$ esterase levels, all of which were normal. She was treated with 100 $\mathrm{mg}$ hydrocortisone intravenously, the lesions resolving within $18 \mathrm{hr}$, advised to discontinue her tablets and has had no long term sequelae on follow-up.

\section{Discussion}

Angioneurotic oedema and urticaria may occur

*Present address: Sir Patrick Dun's Hospital, Grand Canal Street, Dublin 2. separately or in combination and have been associ- $\vec{\omega}$ ated with underlying infection, autoimmune and lymphoproliferative disorders. Further aetiologicako factors include emotional stress (Chue, 1976), various 3 . food stuffs, inhalants and physical agents. The yellow dye, tartrazine (Makol and Pinnas, 1980) and the parabens (Henry, Tscher and Becker, 1979) 60 present in many medications have also been impli- $-\omega$ cated as causes of allergic reactions. The preparation used by the patient did not contain these additives. $\frac{}{7}$

The offending agent in this patient appeared to be $\overrightarrow{\vec{Z}}$ hyoscine butylbromide; rechallenge was not feasible on ethical grounds. Possible mechanisms include an_ IgE dependent, mast-cell mediated response although $\oplus_{\infty}$ the onset of her symptoms one week after therapy! would suggest an underlying Arthus type reaction. The clinical picture however was in keeping with ans immediate type hypersensitivity response. Alterna- $-\frac{\partial}{0}$ tively, various drugs can precipitate angioneurotico oedema and/or urticaria by causing histamine ${ }_{0}^{\circ}$ release, but we can find no evidence that hyoscine butylbromide has this property.

\section{Acknowledgment}

We would like to thank Dr A. Scott for her valuable advice in writing this paper.

\section{References}

CHUE, P.W. (1976) Acute angioneurotic oedema of the lipsi and tongue due to emotional stress. Oral Surgery, 41, 734.윽

HenRY, J.C., TsCher, E.H. \& BeCKer, L.E. (1979) Contact urticaria to parabens. Archives of Dermatology, 115, 1231 .음

MaKol, G.M. \& PINNAS, J.L. (1980) Angioneurotic oedema and urticaria associated with yellow dye in medications
Arizona Medicine, 37,79 .

Reichel, H. (1976) Physiological conditions controlling then activity of an orally administered parasympatholytic drug: hyoscine m-butylbromide. Current Medical Research and Opinion, 3, 697. 